\title{
The Relationship between Phonemic Segmentation Skill and EFL Word Recognition - A Review of Literature
}

\author{
Mohammad Husam Alhumsi (Corresponding author) \\ School of Education \& Modern Languages, College of Arts and Sciences, Universiti \\ Utara Malaysia \\ E-mail: husam_1001@yahoo.com \\ Dr. Ahmad Affendi \\ School of Education \& Modern Languages, College of Arts and Sciences, Universiti \\ Utara Malaysia \\ E-mail: affendi@uum.edu.my
}

Received: February 24, 2016 Accepted: March 2, $2016 \quad$ Published: April 7, 2016

doi:10.5296/ijl.v8i2.9097ＵRL: http://dx.doi.org/10.5296/ijl.v8i2.9097

\begin{abstract}
Beginning readers apparently face difficulties when they are to learn English language skills, particularly reading skill. This research paper reviews the literature regarding the relationship between the skill of phonemic segmentation and EFL word recognition. It addresses three main issues: the position of phonemic segmentation skill in literature, the relation between phonological awareness and ability to read, and the skill of word recognition and learning to read. The aim of this paper is to precisely explore the nature of the relation of phonemic segmentation skill and beginning readers' word recognition. The leading research question for this paper is: What is the relationship between the skill of phonemic segmentation and beginning readers' EFL word recognition? To answer the research question, the researcher will review literature to explore that relation. The researcher will conclude that the relationship between the skill of phonemic segmentation and word recognition has received substantial concern in literature. It has significant effects on learning to read as well. Calls for implications, recommendations and intervention programs will be presented accordingly.
\end{abstract}

Keywords: Phonemic Segmentation Skill, EFL Word Recognition, Beginning Readers, English as a Foreign Language (EFL) 


\section{Introduction}

The fundamental and foundational associations required for gaining the success of later reading are provided by the reading skills acquired during the preschool stage. It is important to note that oral language skills have a pivotal role to play in the acquisition of reading skills during the early years of students' education in elementary schools. The National Institute for Literacy (NIFL, 2007) defined the skill of reading as a complicated system that derives meaning from print. This system requires certain steps. First, learners should have the knowledge of understanding the association between sounds and letters of the language. Second, they should be able to decode unfamiliar words. Third, they should be able to have the skill of fluent reading. Fourth, learners are required to have adequate foundational background as well as vocabulary in order to encourage their comprehension while reading. Fifth, in order to build up meaning from text, learners actively should develop relevant strategies. Finally, they should develop and maintain their motivation to read.

The above definition provides an obvious indication that phonemes play a radical role in reading acquisition. It is important to note that scholars have interchangeably used phonological awareness and phonemic awareness terms. Being described in general terms, phonological awareness refers to phoneme understanding. Thus, Kirby, Parrila, and Pfeiffer (2003) pointed out that phonological awareness refers to "the awareness of the sound structure of words and the ability to manipulate sounds in words" (p. 453). As for phonemic awareness, it is a particular constituent that lies under the umbrella of phonological awareness. Hence, phonemic awareness has been referred to as "the tasks that require children to identify or manipulate the phonemes in words that are presented orally" (Torgesen, 2004, p. 4). With respect to phonological awareness, it encompasses several components such as phoneme deletion, phoneme categorization, phoneme segmentation, sound blending, syllabic awareness, and rhyme awareness. Young learners demonstrate each of these constituents with the help of their oral language. It is interesting to note that young learner's development of expressive and receptive oral language substantially becomes critical once they enter the stage of preschool. As a result, beginning reading skills will be initiated from a phonological background within the early years of students in their formal education (Dahmer, 2010).

In fact, a number of researchers firmly contended that young learners who confront difficulty in the process of detecting or manipulating sounds in words will face problems towards the process of learning to read (Hatcher et al., 2004; Vellutino, Fletcher, Snowling \& Scanlon, 2004; Anthony \& Farncis, 2005; Snowling, 1998; Share, 1995). Therefore, such claim provides a legitimate association between phonological awareness and reading development. In other words, young learners who lack the skill of phonemic awareness probably suffer from poor reading in later stages. Hence, it is necessary to check for remedies to enhance young learners' phonological skills to become better readers in future.

Researchers claimed that various types of difficulties at word level are experienced by Arab learners who practice English as a foreign language when they read English texts (Ryan \& Meara 1991; Brown \& Haynes 1985). Particularly, Fender (2003) contended that Arab learners are likely to have hardship concerning the pre-lexical word recognition processes; it 
refers to their ability to recognize the written form of a word or its meaning to operate other skills such as the word's meaning, syntactic information, and other pragmatic connections. These processes function at a pre-lexical stage. They are essential for identifying and operating a word as well (Vellutino et al. 1994; Siedenberg 1992). According to MacDonald (2000), their knowledge is rigorous for comprehension and reading fluency of a foreign language.

\section{Background of the Study}

Reading is a complicated process that encompasses learning a confusing code of letters and sounds known as the alphabetic principle. Literature has shown that some young learners have difficulties concerning this part in the development of reading since they experience difficulty related to phonemic awareness (Adams, 1990; Shanahan \& Lonigan, 2013; NELP, 2008; NICHD, 2000). To be more specific, Zorfass and Urbano (2008) argued that the main cause of struggling readers' poor performance is the lack of foundation skills. Such performance represented by struggling readers involves learners who suffer from learning disabilities, learners of English language, and others who are exposed to reading failure. Having no strong foundation skills, young learners will have the probability to struggle in learning areas that require reading, such as social studies, English language arts, math, and science when entering middle school (Zorfass \& Urbano, 2008).

It is interesting to note that a high standard level in early education is rigorous for all learners to ensure their success that leads to long-term academic learning. Beginning readers must understand the reason behind learning the skills of reading and writing in order to reach an excellent level in their own literacy development. Young learners flexibly have to learn ways and instructions to use in their growing knowledge through active engagement in the reading process development. They can all carry a strong foundation for the development of literacy and reading skill when opportunities are open to them to be purposefully engaged in early written language activities (Storch \& Whitehurst, 2002; Dahmer, 2010).

Furthermore, it has been noted that reading process is an ongoing process and builds upon a vast range of growing skills. According to Ballantyne, Sanderman, and McLaughlin (2008), young learners who have opportunities to initiate skills of basic background in language and literacy in preschool are ready to enter kindergarten to learn to reading and writing skills. Learners will develop and flourish as readers with the help of the foundational skills that put them in their right place on their learning pathway.

In the same thread, Nesdale, Herriman, and Tunmer (1984) conducted a study that included various tasks and procedures. In their study, they examined the development of the ability of young learner to divide spoken words into their phonemic components. Much research has been seemingly stimulated that learner's explicit knowledge which speech consists of phonemic segments is likely to be an important prerequisite for having the ability to the process of learning to read. Gough and Hillinger (1980) argued that the lack of phonological awareness may exclusively be the hindrance to reading acquisition. To support this argument as reported in various studies, in accordance with Share, Jorm, Maclean, and Matthews (1984), positive correlations existed between phonological awareness and reading 
achievement. Additionally, predictive correlations existed between measures of phonological awareness gained before the beginning of reading instruction and later reading achievement.

However, Jordanian first graders often experience difficulty when attending to meet these foundational skills. This can be due to the weakness they have in English phonological awareness which may be linked to the lack of the skills of phonemic awareness, particularly the phonemic segmentation skill. It is evident that Jordanian EFL children are likely to depend on their mother tongue language when they come to read English isolated words or read English texts. This leads to "a slower and perhaps even less accurate [EFL] word recognition" (Fender, 2003, p. 294). They should depend on skills in English phonological processing rather than their Arabic phonological system in order to carry their English word recognition (Perfetti, 1991; Gough \& Walsh, 1991).

Consequently, more attention has to be provided to have Jordanian young learners develop their phonological awareness of English and to acquire a faster and a more accurate EFL word recognition. To arguably achieve this aim, explicit phonological instruction, particularly phonemic segmentation skill has to be taken place in real classroom environment (Ball \& Blachman 1991; Snow, Burns, \& Griffin, 1998). This poses challenges to the language argument in which phonological awareness is only acquired by nature (Foorman \& Liberman, 1989). Thus, the aim of this current paper is to test the hypothesis in which explicit instruction of the phonemic segmentation skill can have positive effect on Jordanian beginning readers' EFL word recognition. If this test becomes true, a crucial implication can be gained. It is related to theoretical implication in a way that it is corroborated regarding the issue of ability of learning of phonological awareness.

\section{Research Questions}

In this paper, there is only one major question: What is the relationship between the skill of phonemic segmentation and beginning readers' EFL word recognition?

\section{Literature Review}

This section addresses three main issues. First, it tackles the place of phonemic segmentation skill in literature. Second, it discusses the relation between phonological awareness and ability to read, and finally, it tackles the skill of word recognition and learning to read. The aim of this paper is to precisely explore the nature of the relation of phonemic segmentation skill and beginning readers' EFL word recognition.

\subsection{The Position of Phonemic Segmentation Skill in Literature}

Phonemic awareness is considered one component of the large umbrella of phonological awareness. It refers to the ability of the learner to recognize, identify and manipulate phonemes in spoken words. Research found that this essential component of reading is the only strongest indicator for young learner's success regarding the issue of learning to read (NICHD, 2000). Hence, phonemic awareness basically depends on oral language as well as serving as having a foundational feature for reading development. Young learners who lack the ability to hear and work with the phonemes of spoken words will face hardships in the 


\section{Macrothink}

International Journal of Linguistics

ISSN 1948-5425

2016, Vol. 8, No. 2

learning process of how connecting these phonemes (sounds) to graphemes (letters) when they experience them in printed words.

Chard and Dickson (1999) contended that phonemic awareness is the most crucial and complicated level of phonological awareness. The place of phonemic segmentation skill lies in this complicated level of phonemic awareness; it is one of several skills related to phonemic awareness as shown in figure 1 below.

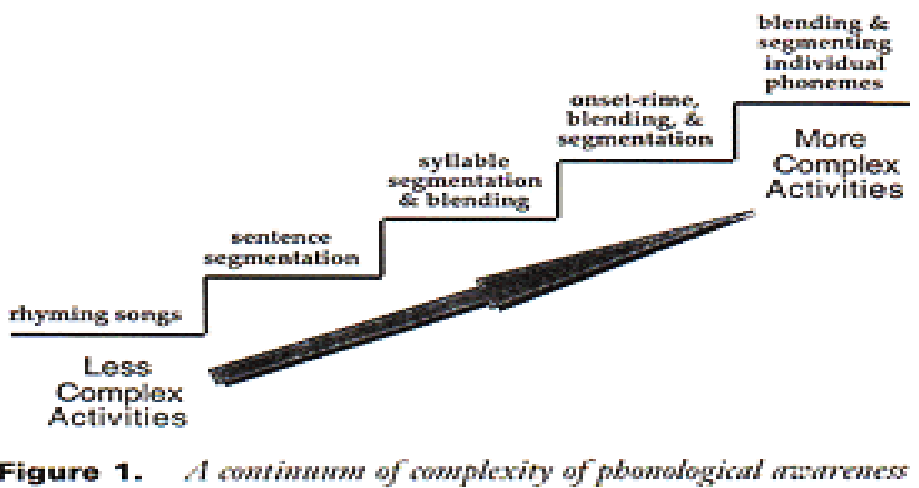
scricisies.

Figure 1. Continuum of Phonological Awareness Complexity, Adopted from (Chard \& Dickson, 1999)

In order to train young learners on phonemic segmentation skill, the instruction can be taught as follows: Young learners can learn how to divide words into phonemes (e.g. "If I say cat, you should say /k/, /a/, /t/"). Then, they can say the word slowly (e.g. they should say in such way: Kkkkkkk aaaaaa tttttt) Then, they say "cat"). Thus, various studies that tackle various tasks and procedures have examined the ability of young learner's development to divide or segment spoken words into their phonemic components (Nesdale, Herriman \& Tunmer, 1984).

Learners who effectively demonstrate phonemic awareness are those readers who can successfully identify the small sounds in words. Additionally, those can "have the ability to notice, mentally grab hold of and manipulate these smallest chunks of speech" (Yopp \& Yopp, 2000 , p. 130). It has been suggested that "children with strong phonological awareness can detect, match, blend, segment and manipulate speech sounds" (Lane et al., 2002, p. 101).

Furthermore, learners are required to understand sound patterns to assist them with decoding words. They need to have the ability to join together different sound patterns to produce a separate sound. In his study, Manyak (2008) proposed that the understanding of sound patterns makes early phonetics instruction fruitful for young learners. It also facilitates the ability of young learners to combine letter sounds together when they decode words. It is interesting to note that the ability to successfully use sound manipulation by blending and segmenting sounds in words can result in higher word knowledge. 
Reviewing the literature, two experiments investigated whether teaching phonemic segmentation with articulatory gestures had more powerful effects than teaching without having these articulatory gestures. In the first experiment, Wise, Ring, and Olson(1999) investigated whether phonics-based reading instruction helped the stage of second graders of struggling readers to fifth graders improve their reading when including the instruction of articulatory awareness compared to instruction without articulation. There was no advantage offered by the articulatory awareness constituent despite the fact that the students in both conditions widely acquired in phonemic awareness, word recognition, and decoding compared to students that do not receive these treatments.

As for the second experiment, Castiglioni-Spalten and Ehri (2003) conducted a research with younger kindergartners who received only phonemic segmentation instruction; there was no reading instruction done as part of the treatment. In their study, one group was taught phonemic awareness in which they segment words with articulatory pictures. As for the other group, they were taught phonemic awareness with blank markers. It should be noted that letters were not part of training. However, young learners already identified the names of the letters that described the sounds being manipulated. As a result, the transfer of phonemic awareness training to word reading and spelling could be tested. It is important to note that substantial gains made by two treatment groups considerably achieved following a training program compared to those who have no treatment in the control group. There was no observed benefit of articulation beyond that of blank markers in gaining phonemic awareness or its transfer to spelling. This was consistent with the study conducted by Wise et al. (1999).

\subsection{Phonological Awareness and Learning to Read}

Phonological awareness has only lately acquired the due attention despite its profound area in the field of literacy. There were burgeoning discussions in the past century have addressed the relationship between the awareness of the sounds of the language and the ability to read. A number of psychologists noticed that young learners who struggle with reading could neither divide nor combine the sounds of a spoken word together during the 1940s. Highlighting the significant relationship between the awareness of sounds and learning to read, psychological research had been intensified in the 1960s and 1970s (Goswami, 2000; Ehri, 1989; Olofsson $\&$ Niederose, 1999). Furthermore, the report presented to the Congress by the National Reading Panel (1998) in USA strongly supports assisting young learners in hearing sounds in words, the knowledge of the letters of the alphabet, and the knowledge of letter - sound associations in order that they can read words (Snow et al. 1998).

Anthony and Francis (2005) pointed out that phonological awareness involves kills such as basic phonological skills like judging whether two words rhyme, the ability to manipulate phonemes, and phoneme awareness. As for Chard and Dickson (1999), the manipulation of phonological awareness means that phonological awareness activities can be classified into three levels with respect to complexity: Such activities include initial rhymes, rhyming songs, and sentence segmentation that shows awareness that speech can be segmented into single words which in turn fall within the least complex level. At the medium level, there are activities related to segmenting words into syllables, blending syllables into words, 
segmenting words into onsets and rimes and blending onsets and rimes into words. In the final level, there is the most complicated level of phonological awareness which is known as phonemic awareness. This type of complicated level is the ability to manipulate phonemes in a way that enables young learners to segment, blend, or change individual phonemes within words to make new ones. (See Figure 1)

Like other researchers, Schuele and Boudreau (2008) stated that phonological awareness can be referred to an umbrella term that involves a variety of skills involving phonemic awareness. Phonemic awareness can be defined as the learner's ability to manipulate individual phonemes or sound of a given language (Yopp, 1992).

The question that should be posed is that: "Is there a relation between phonological awareness and learning to read?" Such question has been continually addressed throughout literature for a number of years. To get to fruitful answer, a review of literature has been made to have a quick look at this relation. Reading skill should be entrance to this debate. Torgesen (1998) noted that the ability to learn and comprehend from printed text is known as reading achievement. Moats (2000) considered reading ability as crucial skill in which all young learners are required to gain to reach that needed level of success in school and in their life future. Young learners will unavoidably not have the required advantages of their educational experience if they do not succeed in reading skill. It has been noted that large number of people would agree that the most important responsibility of instructors and teachers is to teach young learners how to read (Moats, 2000).

In research, this has been substantially demonstrated in a way that phonological awareness has significant correlation with the ability to read. It is evident that reviewing the following studies will display that correlation. Wagner, Torgesen, and Rashotte (1994) conducted a longitudinal study concerning phonological processing and reading. It was evident that young learners who started first grade without having the appropriate skills in phonological awareness will not continually follow their peers with regard to the skills of decoding and word recognition during their whole life in their elementary schools. Catts (1993) conducted a research on the relationship between impairments of speech language, particularly the lack of phonological awareness and disabilities of reading. According to Catts' (1993) prediction, it is important to note that kindergarteners' language abilities would be instantly linked to reading achievement in first and second grade.

Another prediction by Catts (1993) was that the skills of phonological awareness would effectively reflect the consequence of young learners' ability with respect to reading skill. In his study, deletion and blending tasks were introduced to evaluate the participants' abilities in phonological awareness. Due to their ability to measure phoneme and syllable awareness, these particular tasks had been selected. Young learners' reading ability was measured when they entered first and second grade. The assessment of reading was done through particular skills such as comprehension tasks, word recognition, and speed and accuracy of word recognition. The results of Catts' (1993) study showed that the participants' language impaired group significantly got below their peers' level concerning reading achievement. It is important to indicate that these findings further support the relationship between the ability 
of reduced reading and language impairments. The same researcher pointed out that his research discloses "phonological awareness deficits lie near the core of reading disabilities in young children” (p. 955).

On the other hand, Swank and Catts (1994) investigated the particular effect of phonological awareness on the first graders' decoding ability. The aim of that research was to determine whether the measures of phonological awareness have an impact on predicting the decoding ability of first graders. Both researchers used four tasks in phonological awareness to evaluate the ability of the first graders and they chose these four tasks since its relationship predictively related to reading ability in later stages. Activities such as blending, deletion, segmentation, and categorization tasks involved in their study. Additionally, activities of word attack and word identification are two ways that assessed reading skill. As for phonological awareness measures of first grade at the onset level, they were compared with the ability of decoding at the end of first grade. The period was approximately six months that encompassed the phonological awareness introduction and the decoding measures. At the end of their study, Swank and Catts (1994) found that phonological awareness measures are strong predictors of decoding. Their study determined that, in discriminating decoders, the particular deletion skill of phonological awareness considered the most effective measure. Both researchers pointed out that their study is crucial for the identification of deficient decoding as well as disabilities of reading in early stages.

In another research, Catts, Fey, Zhang and Tomblin (2001) conducted a longitudinal study that examined the kindergarten predictors of reading performance of second grade. In their study, the researchers determined the measures of language in which they were fruitful in the prediction of the difficulties of reading in future. In order to improve reading performance, there has been research study in the area disability of reading in a way that investigates the capability of reading so that phonological awareness skills can be remediated (Torgesen, 2002). Further, Schuele and Boudreau (2008) argued that the critical purpose of phonological awareness instruction or intervention has a beneficial aim, given a remarkable assistance in the literacy acquisition, particularly in the area of decoding words.

In the same thread, Schuele and Boudreau (2008) pointed out that many different studies have given evidence that phonological awareness can be improved. It will also lead to the increase of reading ability and word decoding. In this paper, the researcher discussed the findings of two studies that sought to determine the significant effect of phonological awareness training in order to increase learners' ability towards reading skill, specifically to know which elements of the phonological awareness are most useful in a program to be the most effective one.

First, Gillon and Dodd (1995) conducted a study concerning the effects of training phonological and semantic syntactic skills on ten to twelve year old students' reading skill. The researchers investigated this effect on ten students. The ten students who identified as having disabilities in reading, particularly in the areas of syntactic, phonological and semantic processing skills, participated in this study. It should be noted that all participants were assessed for intelligence test. They scored above average on the Test of Nonverbal 
Intelligence and the Peabody Picture Vocabulary Test-revised. The participant students involved in two training programs. The first program introduced explicit instruction in phonological processing skills. As for the other, it provided instruction in semantic, syntactic skills. At the end of their research, it has been found that the study proposed that reading disabilities are the results of the lack of phonological and semantic-syntactic skills and this lack can be successfully remediated.

With respect to the second study, Gillon (2000) investigated the effectiveness of a phonological intervention program. She hypothesized that children provided with explicit intervention in phonological awareness would get more benefits in their reading ability when compared to children that received intervention in traditional speech-language and children that received minimal intervention. In her study, there were ninety one participant children whose ages were five to seven years. It is important to indicate that the participants were placed in two intervention programs. The first was a traditional speech-language intervention program. This program focused on improving articulation or language skills. It is also an integrated program of phonological awareness designed to boost the phonological structure awareness of spoken language as well as increasing a conscious knowledge of letter-sound 12 correspondences.

On the other hand, the second program focused on the participants placed in a minimal intervention control program. All participants were given pre and post intervention assessment. Therefore, reading ability, phonological awareness and speech production were measured using a battery standardized assessments. Gillon's (2000) findings revealed that an explicit program in phonological awareness can significantly boost the skills of reading accuracy as well as reading comprehension with regard to children with language impairments. The intervention program focused on skills developed at the phonemic level; activities in phonological awareness were integrated with grapheme (letter)-phoneme (sound) knowledge training.

It is important to note that segmenting phonemes activities are given particular attention. Thus, a strong consensus in the provided research proves that there is a significant improvement of reading ability and this can be improved via explicit intervention of phonological awareness. To support such a claim, Torgesen (2002) noted that the most beneficial programs that are intensive, phonemically explicit instructions, and provided in the initial preschool to 13 children that struggle with reading will be used to increase phonological awareness.

As mentioned above, one can easily notice that the children can receive the most explicit phonological instruction at the most intensive intervals in a way that young learners can make substantial improvements in their reading skills at the level of a word. To conclude, the above research findings provide us with the required knowledge needed concerning the development of valid and effective reading instruction or prevention programs (Torgesen et al., 1999) that pave the way to improve reading ability. 


\subsection{The Skill of Word Recognition and Learning to Read}

Within the relation between phonological awareness and reading, young learners who have instructions in English phonemic awareness have a strategy to help them develop their reading skill. To transfer skills of oral language to initial reading needs purposeful skills provided in a particular manner so that students can be provided with a remarkable understanding of the process.

Given the focus on the smallest unit of sound, a phoneme, learners have an opportunity to link a sound with its graphic representation of a letter. Learners can identify sound- letter association by understanding the alphabetic code of the English language to start developing such relation. It has been argued that "The phoneme is the most critical segment for grasping the alphabetic principle and learning to use it" (Shankweiler \& Fowler, 2004, p. 487). Thus, each of the letters has a particular sound that helps learners recognize the words introduced and needed to be decoded. Many different researchers affirmed that learning to read process includes representing letters to their individual phonemes (Gray \& McCutchen, 2006; Foy \& Mann, 2006; Byrne et al., 1996).

In literature, there has been a consensus concerning the "Recognition of the fact that words are composed of sounds is important for the following step within the period of early literacy, namely learning to identify words" (Aarnoutse, Van Leeuwe, \& Verhoeven, 2005, p. 254). When reviewing the aforementioned studies, the development of phonological awareness skill provides a strategy that prepares and helps learners move from a utilized form of oral communication to the following step that requires placing oral sounds into written form.

Moreover, in recent research, the importance of phonological awareness regarding the reading success of a young learner is well documented in literature. For instance, Stahl, Duffy-Hester, and Stahl (2006) affirmed that phonological awareness considers the key that leads to the alphabetic principle development, invented spelling, and word recognition. What helps in understanding how sounds function in isolation and in combinations involves letter knowledge and word knowledge associated with reading on one hand, and spelling knowledge associated with writing, on the other. Goswami (2000) asserted that phonological awareness encompasses the ability to be aware of the phonemic segments represented by letters of the language. This was an essential result because phonological awareness can significantly affect reading abilities in the present and future. Within recent research, its significance as crucial for early reading skill is noticeably evident. For example, Mather, Bos and Babur (2001) pointed out that "Results from longitudinal studies suggest that $75 \%$ of the children who struggle with reading in third grade, particularly with the development of phonological awareness and decoding, will still do poorly at reading at the end of high school" (p. 472).

In the same vein, Whiteley, Smith, and Connors (2007) showed how phonological awareness as an intervention strategy can help young learners read English words. The researchers stated that phonological awareness "supports the acquisition of the alphabetic principle which, in turn, underpins the development of the essential skill of automatic word recognition" ( $p$. 249). Once again, phonological awareness is introduced as an important part of the reading 
process. This particular process is based on the integration of several different skills that lead to the recognition of words.

\section{Conclusion and Recommendations}

This literature review concerning the relation between phonological awareness and learning to read is extensively researched. As for this paper, it aims at investigating the relationship between the skill of phonemic segmentation and EFL beginning readers' word recognition. When reviewing the literature, there is a void regarding the issue of conducting research that involves phonemic segmentation skill separately and shows its relation to the development of EFL beginning readers' word recognition. As shown in literature, phonemic segmentation represents an essential bridge in a way that leads to the development of word recognition.

This current paper recommends that integrating the use of technology, specifically the interactive white board, can facilitate reading process. The following step can be done in conducting research that investigates beginning readers and learners in an environment where an interactive whiteboard exists and can be used specifically for phonemic segmentation instruction. It can be also critical to assess students' word recognition development and introduce such skill in EFL curriculum. Furthermore, intervention programs and duration of the intervention should be short in time and should not spend too much time on phonemic awareness activities (Berg \& Stegelman, 2003).

\section{References}

Aarnoutse, C., Van Leeuwe, J., \& Verhoeven, L. (2005). Early literacy from a longitudinal perspective. Educational Research and Evaluation, 11(3), 253-275. http://dx.doi.org/10.1080/08993400500101054.

Adams, M. (1990). Beginning to read. Thinking and learning about print. Cambridge, MA: MIT Press.

Anthony, L., \& Francis, D. (2005). Development of phonological awareness. American Psychological Society, 14(5), 255-258.

Ball, E., \& Blachman, B. (1991). Does phoneme awareness training in kindergarten make a difference in early word recognition and developmental spelling? Reading Research Quarterly, 26(1), 49-66.

Ballantyne, K., Sanderman, A., \& McLaughlin, N. (2008). Dual language learners in the early years: Getting ready to succeed in school. Washington, DC: National Clearinghouse for English Language Acquisition.

Berg, M., \& Stegelman, T. (2003). The critical role of phonological and phonemic awareness in reading success: A model for early literacy in rural schools. Rural Special Education Quarterly, 22(4), 47-51.

Brown, T. L., \& Haynes, M. (1985). Literacy background and reading development in a second language. In T.H. Carr (Ed.) The development of reading skills. San Francisco: CA: Jossey-Bass. 
Byrne, B., Fielding-Barnsley, R., \& Ashley, L. (1996). What does the child bring to the task of learning to read? A summary of the New England reading acquisition projects. Australian Journal of Psychology, 48(3), 119-123. http://dx.doi.org/10.1080/00049539608259517

Castiglioni-Spalten, M. \& Ehri, L. (2003). Phonemic awareness instruction: Contribution of articulatory segmentation to novice beginners' reading and spelling. Scientific Studies of Reading, 7(1), 25-52. http://dx.doi.org/10.1207/S1532799XSSR0701_03

Catts, H. (1993). The relationship between speech language impairments and reading disabilities. Journal of Speech and Hearing Research, 36(5), 948-958. http://dx.doi.org/10.1044/jshr.3605.948

Catts, H., Fey, M., Zhang, X., \& Tomblin J. (2001). Estimating the risk of future reading difficulties in kindergarten children: A research-based model and its clinical implementation. Language, Speech, and Hearing Services in Schools, 32(1), 38-50. http://dx.doi.org/10.1044/0161-1461(2001/004)

Chard, D. \& Dickson, S. (1999). Phonological awareness: Instructional and assessment guidelines. LD Online, Retrieved February 25, 2016, from http://www.ldonline.org/articles/6354.

Dahmer, M. (2010). Phonological awareness in the kindergarten classroom: How do teachers perceive this essential link from oral communication to reading skill development? Doctoral Dissertations and Projects. Retrieved from http://digitalcommons.liberty.edu/doctoral/

Ehri, L. (1989). The development of spelling knowledge and its role in reading acquisition and reading disability. Journal of Learning Disabilities, 22(6), 356-365. http://dx.doi.org/10.1177/002221948902200606

Fender M. (2003). English word recognition and word integration skills of native Arabic and Japanese- speaking learners of English as a second language. Applied Psycholinguistics, 24, 289-315. http://dx.doi.org/10.1017/S014271640300016X

Foorman, B., \& Liberman, D. (1989). Visual and phonological processing of words: A comparison of good and poor readers. Journal of Learning Disabilities, 22(6), 349-355. http://dx.doi.org/10.1177/002221948902200605

Foy, J., \& Mann, V. (2006). Changes in letter sound knowledge are associated with development of phonological awareness in pre-school children. Journal of Research in Reading, 29(2), 143-161. http://dx.doi.org/10.1111/j.1467-9817.2006.00279.x

Gillon, G. (2000). The efficacy of phonological awareness intervention for children with spoken language impairments. Language, Speech and Hearing Services in Schools, 31, 126-141.

Gillon, G., \& Dodd, B. (1995). The effects of training phonological, semantic, and syntactic processing skills in spoken language on reading ability. Language, Speech, and Hearing Services in Schools, 26, 58-68. http://dx.doi.org/10.1044/0161-1461.2601.58. 
Goswami, U. (2000). Phonological and lexical processes. In D. P. Pearson (Ed.), Handbook of Reading Research (Vol. 3, pp. 251-258). Mahwah, N. J.: Lawrence Erlbaum Associates, Inc.

Gough, P., \& Hillinger, M. (1980). Learning to read: An unnatural act. Bulletin of the Orton Society, 30, 179-196.

Gough, P., \& Walsh, M. (1991). Chinese, phoenicians, and the orthographic cipher of English. In Brady S. and D. Shankweiler (eds.). 199-209.

Gray, A., \& McCutchen, D. (2006). Young readers' use of phonological information: phonological awareness, memory, and comprehension. Journal of Learning Disabilities, 39(4), 325-333. http://dx.doi.org/10.1177/00222194060390040601

Hatcher, P., Hulme, C., \& Snowling, M. (2004). Explicit phoneme training combined with reading instructions helps young children at risk of reading failure. Journal of Child $\begin{array}{llll}\text { Psychology and } & \text { Psychiatry, } & \text { 35(2), }\end{array}$ http://dx.doi.org/10.1111/j.1469-7610.2004.00225.x.

Kirby J., Parrila R., \& Pfeiffer S. (2003) Naming speed and phonological awareness as predictors of reading development. Journal of Educational Psychology, 95(3), 453-464. http://dx.doi.org/10.1037/0022-0663.95.3.453.

Lane, H., Pullen, P., Eisele, M., \& Jordan, L. (2002). Preventing reading failure: Phonological awareness assessment and instruction. Preventing School Failure, 46(3), 101-110. http://dx.doi.org/10.1080/10459880209603354

MacDonald, J. (2000). Grammaticality judgments in a second language: Influences of age of acquisition and native language. Applied Psycholinguistics, 21(3), 395-423. http://dx.doi.org/10.1017/s0142716400003064.

Manyak, P. (2008). Phonemes in use: Multiple activities for a critical process. The Reading Teacher, 61(8), 659-662. http://dx.doi.org/10.1598/RT.61.8.8.

Mather, N., Bos, C., \& Babur, N. (2001). Perceptions and knowledge of preservice and inservice teachers about early literacy instruction. Journal of Learning Disabilities, 34(5), 472-482. http://dx.doi.org/10.1177/002221940103400508.

Moats, L. (2000). Speech to print. Baltimore, Maryland: Paul H. Brookes Publishing Co.

National Early Literacy Panel. (2008). Developing Early Literacy: Report of the National Early Literacy Panel. Washington, DC: National Institute for Literacy. Retrieved from http://lincs.Ed.gov/publications/pdf/NELPReport09.pdf

National Institute for Literacy (2007). Reading facts. Washington, DC: Government Printing Office. Retrieved from http://www.nifl.gov/nifl/fact/reading_facts.html

National Reading Panel (2000). Teaching children to read: An evidence-based assessment of the scientific literature on reading and its implications for reading instruction. Washington, DC: National Institute of Child Health and Human Development. Retrieved February 15, 
2016, from www.nichd.nih.gov/publications

Nesdale, A., Herriman, M., \& Tunmer, W. (1984). Phonological awareness in children. In W. E. Tunmer, C. Pratt, \& M. L. Herriman (Eds.), Metalinguistic Awareness in Children (pp. 36-72). New York: Springer.

Olofsson, K., \& Niederose, J. (1999). Early language development and kindergarten phonological awareness as predictors of reading problems: From 3 to 11 years of age. Journal of Learning Disabilities, 32(5), 464-472. http://dx.doi.org/10.1177/002221949903200512.

Perfetti, C. (1991). The psychology, pedagogy and politics of reading. Psychological Science, 2(2), 70-76. http://dx.doi.org/10.1111/j.1467-9280.1991.tb00102.x.

Ryan, A., \& Meara, P. (1991). The case of the invisible vowels: Arabic speakers reading English words. Reading in a foreign language, 7(2), 531-540.

Schuele, M., \& Boudreau, D. (2008). Phonological awareness intervention: beyond the basics. Language, Speech and Hearing Services in Schools, 39(1), 3-20.

Shanahan, T., \& Lonigan, C. (Eds.) (2013). Literacy in preschool and kindergarten children: The National Early Literacy Panel and beyond. Baltimore: Brookes Publishing.

Shankweiler, D., \& Fowler, A. (2004). Questions people ask about the role of phonological processes in learning to read. Reading and Writing: An Interdisciplinary Journal, 17(5), 483-515. http://dx.doi.org/10.1023/B:READ.0000044598.81628.e6.

Share, D. (1995). Phonological recoding and self-teaching: Sine qua non of reading acquisition. Cognition, 55(2), 151-218. http://dx.doi.org/10.1016/0010-0277(94)00645-2

Share, D., Jorm, A., Maclean, R., \& Matthews. R. (2002). Temporal processing and reading disability, Reading and Writing: An Interdisciplinary Journal, 15(1), 151-178. http://dx.doi.org/10.1023/A:1013876606178.

Siedenberg, M. (1992). Beyond orthographic depth in reading: Equitable division of labor. In R. Frost \& L. Katz (Eds.), Orthography, phonology, morphology and meaning. Amsterdam: North-Holland.

Snow, C., Burns, S., \& Griffin, P. (1998). Preventing reading difficulties in young children. Washington, DC: National Academy Press, 1998.

Snowling, M. (1998). Reading development and its difficulties. Educational and Child Psychology, 15(2), 44-58.

Stahl, S., Duffy-Hester, A., \& Stahl, K. (2006). Everything you wanted to know about phonics. In K. A. D. Stahl \& M. C. McKenna (Eds.), Reading research at work: Foundations of effective practice (Chap. 9). N. Y.: The Guilford Press.

Storch, S., \& Whitehurst, G. (2002). Oral language and code-related precursors to reading: Evidence from a longitudinal structural model. Developmental Psychology, 38(6), 934-947. 
http://dx.doi.org/10.1037/0012-1649.38.6.934.

Swank, L., \& Catts, H. (1994). Phonological awareness and written word decoding. American Speech-Language Hearing Association, $\quad$ 25, http://dx.doi.org/10.1044/0161-1461.2501.09.

Torgesen, J. (1998). Catch Them Before They Fall. American Educator, 22(1, 2), 32-39. http://dx.doi.org/10.1.1.625.8988

Torgesen, J. (2002). Lessons learned from intervention research in reading: a way to go before we rest. Learning and Teaching Reading, 1, 89-103.

Torgesen, J. (2004). Preventing early reading failure. American Educator, 28(3), 6-19.

Torgesen, J., Wagner, R., Rashotte, C., Rose, E., Lindamood, P., \& Conway, T. (1999). Preventing reading failure in young children with phonological processing disabilities: group and individual responses to instruction. Journal of Educational Psychology, 91(4), 579-593. http://dx.doi.org/10.1037/0022-0663.91.4.579.

Vellutino, F., Fletcher, J., Snowling, M., \& Scanlon, D. (2004). Specific reading disability (dyslexia): what have we learned in the past four decades? Journal of Child Psychology and Psychiatry, 45(1), 2-40. http://dx.doi.org/10.1046/j.0021-9630.2003.00305.x.

Vellutino, F., Scanlon, D., \& Tanzman, M. (1994). Components of reading ability: Issues and problems in operationalizing word identification, phonological coding, and orthographic coding. In Lyon, G.R. (ed.). 279-329.

Wagner, R., Torgesen, J., \& Rashotte, C. (1994). The development of reading-related phonological processing abilities: New evidence of bi-directional causality from a latent variable longitudinal study. Developmental Psychology, 30(1), 73-87. http://dx.doi.org/10.1037/0012-1649.30.1.73.

Whiteley, H., Smith, C., \& Connors, L. (2007). Young children at risk of literacy difficulties: Factors predicting recovery from risk following phonologically based intervention. Journal of Research in Reading, 30(3), 249-269. http://dx.doi.org/10.1111/j.1467-9817.2007.00342.x.

Wise, B., Ring, J., \& Olson, R. (1999). Training phonological awareness with and without explicit attention to articulation. Journal of Experimental Child Psychology, 72(4), 271-304. http://dx.doi.org/10.1006/jecp.1999.2490.

Yopp, K., \& Yopp, H. (2000). Supporting phonemic awareness development in the classroom. The Reading Teacher, 54(2), 130-143. http://dx.doi.org/10.1598/RT.54.2.2

Yopp, K. (1992). Developing phonemic awareness in young children. The Reading Teacher, 45(9), 696-703.

Zorfass, J., \& Urbano, C. (2008). A description of foundation skills interventions for struggling middle-grade readers in four urban Northeast and Islands Region school districts (Issues \& Answers Report, REL 2008-No. 042). Washington, DC: U.S. Department of Education, Institute of Education Sciences, National Center for Education. 


\section{Macrothink}

International Journal of Linguistics

ISSN 1948-5425

\section{Copyright Disclaimer}

Copyright for this article is retained by the author(s), with first publication rights granted to the journal.

This is an open-access article distributed under the terms and conditions of the Creative Commons Attribution license (http://creativecommons.org/licenses/by/3.0/). 